\title{
Ethnic differences in body composition and anthropometric characteristics in Australian Caucasian and urban Indigenous children
}

\author{
Masaharu Kagawa ${ }^{1,2}$, Nuala M. Byrne ${ }^{1,2}$, Neil A. King ${ }^{1,2}$, Sebely Pal $^{3}$ and Andrew P. Hills ${ }^{1,2}$ \\ ${ }^{1}$ ATN Centre for Metabolic Fitness, School of Human Movement Studies, Queensland University of Technology, 60 Musk Avenue, \\ Kelvin Grove, Brisbane, QLD 4059, Australia \\ ${ }^{2}$ Institute of Health and Biomedical Innovation, Queensland University of Technology, 60 Musk Avenue, Kelvin Grove, Brisbane, \\ QLD 4059, Australia \\ ${ }^{3}$ School of Public Health, Curtin University of Technology, Perth, WA, Australia
}

(Received 21 July 2008 - Revised 11 February 2009 - Accepted 17 February 2009 - First published online 2 April 2009)

The objective was to compare ethnic differences in anthropometry, including size, proportions and fat distribution, and body composition in a cohort of seventy Caucasian (forty-four boys, twenty-six girls) and seventy-four urban Indigenous (thirty-six boys, thirty-eight girls) children (aged 9-15 years). Anthropometric measures (stature, body mass, eight skinfolds, thirteen girths, six bone lengths and five bone breadths) and body composition assessment using dual-energy X-ray absorptiometry were conducted. Body composition variables including total body fat percentage and percentage abdominal fat were determined and together with anthropometric indices, including BMI $\left(\mathrm{kg} / \mathrm{m}^{2}\right)$, abdominal:height ratio (AHtR) and sum of skinfolds, ethnic differences were compared for each sex. After adjustment for age, Indigenous girls showed significantly $(P<0 \cdot 05)$ greater trunk circumferences and proportion of overweight and obesity than their Caucasian counterparts. In addition, Indigenous children had a significantly greater proportion $(P<0.05)$ of trunk fat. The best model for total and android fat prediction included sum of skinfolds and age in both sexes ( $>93 \%$ of variation). Ethnicity was only important in girls where abdominal circumference and AHtR were included and Indigenous girls showed significantly $(P<0 \cdot 05)$ smaller total/android fat deposition than Caucasian girls at the given abdominal circumference or AHtR values. Differences in anthropometric and fat distribution patterns in Caucasian and Indigenous children may justify the need for more appropriate screening criteria for obesity in Australian children relevant to ethnic origin.

Children: Ethnicity: Body composition: Anthropometry

Indigenous Australians have a higher risk of developing obesity-related health conditions ${ }^{(1,2)}$. A recent study reported that the average age of Aboriginal and Torres Strait Islanders diagnosed with type 2 diabetes mellitus decreased by about 2 years in the period from 1999 to $2005^{(3)}$. Considering the increasing financial burden for the Australian community from obesity and related health problems ${ }^{(4)}$, early screening and prevention strategies for the Indigenous population have been recommended.

To apply effective strategies, a better understanding of morphology and its relationships with body composition and metabolic markers in each ethnic group is essential. In adults, anthropometric indices such as the BMI and waist circumference have been used as indicators of CVD risk ${ }^{(5)}$. Indigenous Australian adults have a different pattern of fat distribution compared with non-Indigenous Australians ${ }^{(6)}$, and, as reported in different ethnic groups ${ }^{(7,8)}$, Aboriginal adults (aged 18-35 years) show different relationships between adiposity and fat distribution to BMI compared with their European counterparts ${ }^{(9)}$.
Comprehensive assessments of the physical characteristics of Indigenous children and adolescents are few and dated ${ }^{(10)}$, and it is important to clarify if screening using the same cutoff points for Caucasian and Indigenous children is appropriate. A lack of understanding of ethnic differences in body size, proportion and fat distribution patterns may lead to misuse or misinterpretation of results obtained from anthropometric indices. Today, the number of Indigenous individuals living a more traditional lifestyle is relatively small compared with the urban Indigenous population who have a more mixed racial background and commonly live in lower socio-economic circumstances compared with most Australian Caucasians.

The aim of the present study was to characterise the anthropometry and body composition of Caucasian and Indigenous children and adolescents living in an urban setting. Previous studies have referenced ethnic differences in relationships between commonly used anthropometric indices, such as the BMI, and accumulated fat in adults ${ }^{(7,8)}$. Due to the paucity of similar studies in children and adolescents ${ }^{(11,12)}$, the present

Abbreviations: AHtR, abdominal:height ratio; DXA, dual-energy X-ray absorptiometry; ISAK, International Society for the Advancement of Kinanthropometry;

ROI, region of interest; $\Sigma$ SF, sum of eight skinfolds; $\Sigma$ TrunkSF, sum of trunk skinfolds.

* Corresponding author: Dr Masaharu Kagawa, fax +61 73138 6030, email m.kagawa@qut.edu.au 
study also examined relationships between fat mass and anthropometric indices in Caucasian and Indigenous children and adolescents.

\section{Methods}

The study was approved by the Human Research Ethics Committee of Queensland University of Technology and adhered to the principles of medical research established by the National Health and Medical Research Council ${ }^{(13)}$. Participants were recruited from primary and secondary schools located in the Brisbane metropolitan area with the majority of Indigenous children recruited through the Aboriginal and Islander Independent Community School (Murri School). Participants were also recruited through flyers, local newspapers and magazines. All participants and their parents or caregivers were given information packages and consent forms were signed before participation.

The study included seventy Caucasian (forty-four boys, twenty-six girls) and seventy-four Indigenous (thirty-six boys, thirty-eight girls) children aged $9-15$ years. The criteria for 'Indigenous' were that a child had at least one parent of 'Indigenous' ancestry or that the Indigenous community recognised the child as a member of that community. Selection criteria were similar to the definition of 'Aboriginal' by Australian law outlined in a previous study ${ }^{(9)}$, that is: (1) Aboriginal descent; (2) self-identification as an Australian Aboriginal; and (3) being accepted as such by the community in which he or she lives or has lived. Children with chronic health problems or taking medication that may have influenced their physical status were excluded from the study.

\section{Anthropometry}

Stature, body mass, eight skinfolds (triceps, subscapular, biceps, iliac crest, supraspinale, abdominal, front thigh, and medial calf), thirteen girths (head, arm (relaxed), arm (flexed and tensed), forearm, wrist, chest, waist (narrowest point), abdominal (the level of umbilicus), gluteal, thigh, mid-thigh, calf (maximum), and ankle), six bone lengths (acromiale-radiale, radiale-stylion, midstylion-dactylion, trochanterion-tibiale laterale, tibiale height, and foot length) and five bone breadths (biacromial, biiliocristal, transverse chest, biepicondylar humerus, and biepicondylar femur) of each participant were measured using the standard protocol by the International Society for the Advancement of Kinanthropometry (ISAK) ${ }^{(14)}$. All participants were asked to wear light clothing, such as shorts and T-shirt, and stature and body mass were measured without shoes and socks. All landmarks and measurements were conducted by a Level 3 (instructor) anthropometrist accredited by ISAK. Intra-tester technical error of measurement (TEM) was calculated for all measures using twenty randomly selected participants. The intra-tester TEM was no greater than $5.0 \%$ for all skinfold measurements and no greater than $1.0 \%$ for other measurements, within the acceptable limits of intra-tester TEM recommended by ISAK for a Level 3 anthropometrist ${ }^{(15)}$.

From the measurements, BMI (body mass $(\mathrm{kg}) /$ stature $\left.(\mathrm{m})^{2}\right)$, abdominal:height ratio (AHtR: abdominal/stature), waist:hip ratio (waist/gluteal) were calculated. In addition, the sum of eight skinfolds $\quad(\Sigma \mathrm{SF}=$ triceps + subscapular + biceps + supraspinale + iliac crest + abdominal + front thigh + medial calf) and sum of trunk skinfolds ( $\Sigma$ TrunkSF $=$ supraspinale + iliac crest + abdominal) were calculated to determine subcutaneous fat distribution pattern. Arm and leg lengths relative to stature were calculated to observe ethnic differences in body proportion, and the physique of participants was determined by calculating a somatotype score ${ }^{(16)}$. Somatotype is a representation of one's physique and is a combination of endomorphy (relative plumpness), mesomorphy (relative muscularity) and ectomorphy (relative linearity) components. Each component was calculated using equations described in the literature ${ }^{(16)}$.

\section{Body composition assessment}

Body composition was assessed using dual-energy X-ray absorptiometry (DXA; Lunar Prodigy Advance, enCORE 2005 version 9.30.044; GE Healthcare, Madison, WI, USA) Each whole-body DXA scan was completed within approximately 6-10 min, depending on the size of the participant and information on bone mineral content $(\mathrm{kg})$, bone mineral density $\left(\mathrm{g} / \mathrm{cm}^{2}\right)$, fat tissue mass, lean tissue mass, total tissue mass (fat + lean tissue mass) of the whole body as well as android and gynoid regions of interest (ROI) were obtained. The android ROI is defined as the 'lower boundary at pelvis cut, upper boundary located at above pelvis cut by $20 \%$ of the distance between pelvis and neck cuts. Lateral boundaries are the arm cuts.' The gynoid ROI is defined as the 'upper boundary below the pelvis cut line by 1.5 times the height of the android ROI. Gynoid ROI height is equal to two times the height of the android ROI. Lateral boundaries are the outer leg cuts.' The DXA scan also provides ratios of fat mass, including: (1) total body fat percentage; (2) android fat percentage; (3) gynoid fat percentage; (4) trunk:total fat ratio; (5) legs:total fat ratio; (6) limbs:total fat ratio; (7) android:gynoid fat ratio. Further, the proportion of android fat relative to total fat mass $\left(P_{\text {android }}=\right.$ android fat/total fat $\times 100)$ was calculated to compare fat deposition in the abdominal region between the study groups.

All statistical analyses were conducted using SPSS software for Windows (version 14.0.0, 2005; SPSS, Inc., Chicago, IL, USA). Ethnic differences in body size (i.e. stature, body mass) and also ratios calculated from anthropometry (for example, BMI) and body composition measurements (for example, body fat percentage) were determined using ageadjusted analysis of covariance for each sex. In order to control for the influence of body size, other anthropometric and body composition variables, including $\Sigma$ SF and total fat tissue mass, were analysed using age- and stature-adjusted analysis of covariance. Anthropometric and body composition variables were transformed to normalise the data before analysis wherever necessary using natural logarithms. The effect size for variables that showed significant differences between ethnic groups was also calculated using Cohen's $d$ using the equation $\left(M_{1} \times M_{2} / \mathrm{SD}_{\text {pooled }}\right.$ where $M=$ mean, and $\mathrm{SD}_{\text {pooled }}=\sqrt{\left(\mathrm{SD}_{1}^{2}+\mathrm{SD}_{2}^{2}\right) / 2}$. Proportions of overweight and obesity were determined using age- and sex-specific Cole et al. criteria $^{(17)}$ and ethnic differences in prevalence of overweight and obesity were compared using the $\chi^{2}$ test. Furthermore, ethnic differences in relationships between 
Table 1. Physical characteristics of Caucasian and Indigenous children (Mean values with their standard errors and ranges)

\begin{tabular}{|c|c|c|c|c|c|c|c|c|c|c|c|c|}
\hline \multirow{3}{*}{$\begin{array}{l}\text { Sex... } \\
\text { Ethnicity... }\end{array}$} & \multicolumn{6}{|c|}{ Boys } & \multicolumn{6}{|c|}{ Girls } \\
\hline & \multicolumn{3}{|c|}{ Caucasian $(n 44)$} & \multicolumn{3}{|c|}{ Indigenous ( $n$ 36) } & \multicolumn{3}{|c|}{ Caucasian ( $n$ 26) } & \multicolumn{3}{|c|}{ Indigenous ( $n$ 38) } \\
\hline & Mean & SE & Range & Mean & SE & Range & Mean & SE & Range & Mean & SE & Range \\
\hline Age (years) & $12 \cdot 1$ & 0.2 & $10-15$ & $12 \cdot 1$ & 0.3 & $9-15$ & $11 \cdot 4^{*}$ & 0.3 & $10-15$ & $12 \cdot 2$ & 0.3 & $10-15$ \\
\hline Stature $(\mathrm{cm})$ & $155 \cdot 1$ & 1.7 & $132.1-179.5$ & 154.7 & $2 \cdot 0$ & $128 \cdot 2-180 \cdot 6$ & $152 \cdot 9$ & $2 \cdot 1$ & $135 \cdot 0-177 \cdot 7$ & 154.5 & 1.6 & $127 \cdot 7-169 \cdot 3$ \\
\hline Body mass $(\mathrm{kg})$ & $49 \cdot 2$ & $2 \cdot 1$ & $27 \cdot 1-103 \cdot 8$ & 50.7 & $2 \cdot 7$ & $26 \cdot 2-91 \cdot 7$ & $47 \cdot 0$ & 1.9 & $32 \cdot 4-66.5$ & $56 \cdot 7$ & $2 \cdot 9$ & $25 \cdot 6-88 \cdot 1$ \\
\hline $\mathrm{BMI}\left(\mathrm{kg} / \mathrm{m}^{2}\right)$ & $20 \cdot 1$ & 0.6 & $13 \cdot 7-32 \cdot 2$ & $20 \cdot 9$ & 0.9 & $14.9-34.9$ & $20 \cdot 0$ & 0.5 & $16 \cdot 1-25 \cdot 7$ & $23 \cdot 3$ & 0.9 & $14.5-34.0$ \\
\hline Total body fat percentage (\%) & $22 \cdot 2$ & 1.5 & $5 \cdot 8-45 \cdot 7$ & 23.4 & 1.9 & $5 \cdot 3-46 \cdot 1$ & $29 \cdot 2$ & 1.6 & $12 \cdot 6-43 \cdot 0$ & 33.2 & 1.7 & $13 \cdot 6-48 \cdot 2$ \\
\hline Total tissue mass $(\mathrm{kg})$ & $47 \cdot 1$ & $2 \cdot 1$ & $25 \cdot 7-100 \cdot 1$ & $48 \cdot 4$ & $2 \cdot 6$ & $24.8-87.9$ & 44.4 & 1.9 & $28 \cdot 6-63 \cdot 6$ & $54 \cdot 2$ & $2 \cdot 8$ & $24 \cdot 2-84 \cdot 7$ \\
\hline Total fat tissue mass $(\mathrm{kg})$ & 11.6 & $1 \cdot 2$ & $1 \cdot 6-35 \cdot 3$ & $12 \cdot 7$ & 1.6 & $3 \cdot 0-38 \cdot 6$ & 14.0 & $1 \cdot 1$ & $5 \cdot 1-28 \cdot 3$ & $20 \cdot 3$ & 1.9 & $5 \cdot 1-39 \cdot 8$ \\
\hline Android fat tissue mass (kg) & 0.8 & 0.1 & $0.07-2.9$ & 0.9 & 0.1 & $0.2-3.5$ & 1.0 & 0.1 & $0.2-2.5$ & 1.6 & 0.2 & $0.3-3 \cdot 7$ \\
\hline Bone mineral content $(\mathrm{kg})$ & 1.8 & 0.1 & $1 \cdot 2-3 \cdot 3$ & 1.9 & $0 \cdot 1$ & $0.9-3.4$ & 1.8 & 0.1 & $1 \cdot 1-2 \cdot 9$ & $2 \cdot 0$ & $0 \cdot 1$ & $0.8-3.4$ \\
\hline Bone density $\left(\mathrm{g} / \mathrm{cm}^{2}\right)$ & 1.00 & 0.01 & $0.85-1.19$ & 1.01 & 0.02 & $0.86-1.25$ & 1.01 & 0.01 & $0.89-1.26$ & 1.02 & 0.02 & $0.83-1.31$ \\
\hline Sum of skinfolds $(\mathrm{mm}) \dagger$ & 108.5 & 9.2 & $29 \cdot 8-270 \cdot 2$ & $115 \cdot 9$ & 11.8 & $43 \cdot 4-275 \cdot 6$ & 153.7 & $10 \cdot 7$ & $56 \cdot 7-237 \cdot 0$ & $181 \cdot 8$ & $12 \cdot 1$ & $62 \cdot 1-293 \cdot 7$ \\
\hline Sum of trunk skinfolds $(\mathrm{mm}) \dagger$ & 14.4 & 1.5 & $3-38.0$ & $16 \cdot 7$ & 1.9 & $4 \cdot 8-38 \cdot 0$ & $19 \cdot 2$ & 1.6 & $5 \cdot 6-8 \cdot 2$ & $25 \cdot 0$ & 1.8 & $7 \cdot 6-42 \cdot 4$ \\
\hline Proportion of overweight (\%) & \multicolumn{3}{|c|}{$25 \cdot 0$} & \multicolumn{3}{|c|}{$30 \cdot 6$} & \multicolumn{3}{|c|}{$7 \cdot 7^{\star}$} & \multicolumn{3}{|c|}{39.5} \\
\hline Proportion of obese (\%) & \multicolumn{3}{|c|}{9.1} & \multicolumn{3}{|c|}{13.9} & \multicolumn{3}{|c|}{$0.0^{*}$} & \multicolumn{3}{|c|}{23.7} \\
\hline Somatotype scores $\ddagger$ & \multicolumn{3}{|c|}{$3.4-5 \cdot 1-2.9$} & \multicolumn{3}{|c|}{$3 \cdot 9-5 \cdot 2-2 \cdot 8$} & \multicolumn{3}{|c|}{$4 \cdot 5-4 \cdot 4-2 \cdot 6$} & \multicolumn{3}{|c|}{$5 \cdot 6-4 \cdot 7-1 \cdot 8$} \\
\hline
\end{tabular}

* Value was significantly different from that of the Indigenous girls after controlling for the effects of age and stature $(P<0.05)$.

†One Caucasian boy declined to have his iliac crest skinfold thickness measured; therefore forty-three Caucasian boys were included in sum of skinfolds and sum of trunk skinfolds.

$\ddagger$ Endomorphy (relative plumpness), mesomorphy (relative muscularity) and ectomorphy (relative linearity) components. 
body fat variables from DXA and selected anthropometric indices were determined using the general linear model. Body fat variables used in the analysis were: (1) total fat tissue mass and (2) abdominal fat tissue mass which was derived from android ROI; anthropometric variables used in this analysis included body mass, BMI, $\Sigma$ SF, $\Sigma$ TrunkSF, abdominal circumference and AHtR. Age and ethnicity ( 1 for Indigenous and 0 for Caucasians) were included as covariates to examine their influences on the relationships. Considering a previous suggestion that application of ratios may not be useful to define obesity $^{(18)}$, relationships were assessed using absolute mass instead of body fat percentage or android fat percentage. The equations were proposed with adjusted correlation coefficients $\left(R_{\mathrm{ad}}^{2}\right)$ and standard error of estimates (SEE).

\section{Results}

Table 1 shows demographic information of the study groups. Caucasian girls were significantly $(P<0.05)$ younger than their Indigenous counterparts; however, after controlling for age, no ethnic differences in mean stature, body mass, BMI and body fat percentage were observed. After adjusting for age and stature, body composition variables obtained from DXA, which included bone mineral content, bone mineral density and total and android fat tissues, as well as $\Sigma$ SF and $\sum$ TrunkSF from anthropometry, were comparable between ethnic groups. However, using the Cole et al. ${ }^{(17)} \mathrm{BMI}$ criteria, a significantly greater proportion of Indigenous girls were classified as overweight (Caucasian, 7.7\%; Indigenous, $39.5 \%$ ) and obese (Caucasian, 0\%; Indigenous, 23.7\%). These differences were not evident in boys. The mean somatotype for Caucasian boys was balanced mesomorph and for
Indigenous boys, endomorphic mesomorph, a physique with greater fat deposition in the latter group. In girls, both groups had a mean somatotype of mesomorphic endomorph, although Indigenous girls showed a greater endomorphy.

Ethnic differences in subcutaneous fat distribution and other anthropometric variables after adjustment for age and stature are shown in Figs. 1-3. Despite a tendency for higher skinfold measures in Indigenous children, the only significant difference was for subscapular skinfold thickness in girls $(P<0.05)$ (Fig. 1). Indigenous girls also showed significantly greater $(P<0 \cdot 05)$ trunk circumferences (Fig. 2). Indigenous children also showed significantly greater $(P<0.05)$ forearm lengths (radiale-stylon and midstylion-dactylion) (Fig. 3). The larger frame size of Indigenous girls was confirmed by longer acromiale-radiale measures and wider biacromial and bi-iliocristal breadths $(P<0 \cdot 05)$. All significant variables in Indigenous girls showed medium to large effect sizes, between 0.56 (midstylion-dactylion length) and 0.83 (subscapular skinfold and waist circumference) using Cohen's $d$. In boys, the effect size was smaller (Cohen's $d=0 \cdot 2$ ).

Ethnic differences in anthropometric and body composition ratios are shown in Table 2. As seen in Fig. 3, Indigenous children had longer arms relative to stature compared with Caucasian children $(P<0.05$; Cohen's $d$ : boys $=1 \cdot 0$, girls $=0.63)$ and Indigenous girls had significantly $(P<0.05)$ greater AHtR and waist:hip ratio, suggesting greater abdominal fat accumulation. However, the effect size from the waist:hip ratio was smaller (Cohen's $d=0 \cdot 22$ ) compared with that for the AHtR (0.82). This finding of greater fat deposition in the trunk was consistent with DXA results (trunk:total fat mass ratio $(P<0.05)$; Cohen's $d$ : boys $=0.67$; girls $=0.99$; limbs: trunk fat mass ratio $(P<0.05)$; Cohen's $d$ : boys $=0.83$;

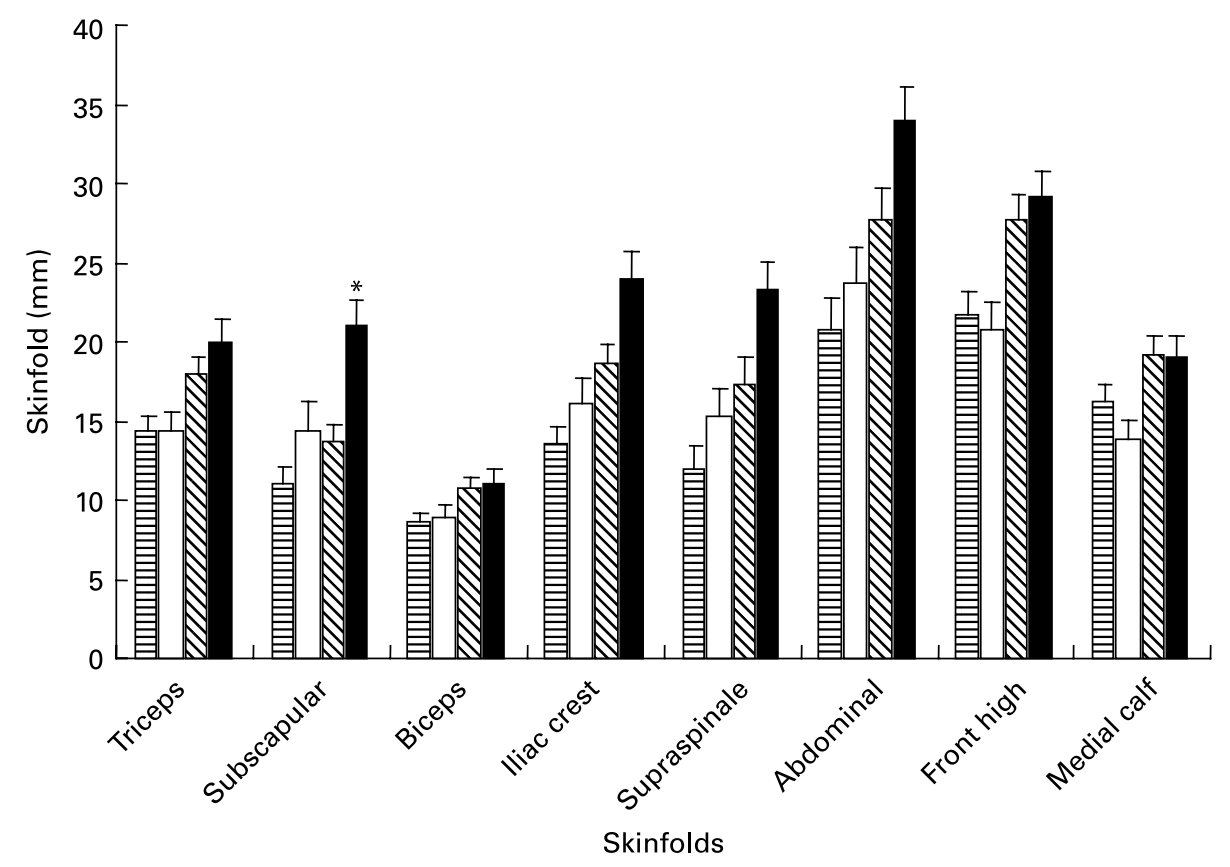

Fig. 1. Ethnic differences in age- and stature-corrected skinfolds. (目), Caucasian boys ( $n$ 44); ( $\square$ ), Indigenous boys ( $n$ 36); ( $\mathbb{\nabla}$ ), Caucasian girls ( $n$ 26); $(\square)$, Indigenous girls ( $n$ 38). Values are means, with standard errors represented by vertical bars. One Caucasian boy declined to have his iliac crest skinfold thickness measured; therefore forty-three Caucasian boys were included for iliac crest. * Mean value was significantly different from that of the Caucasian girls after controlling for the effects of age and stature $(P<0.05)$. 


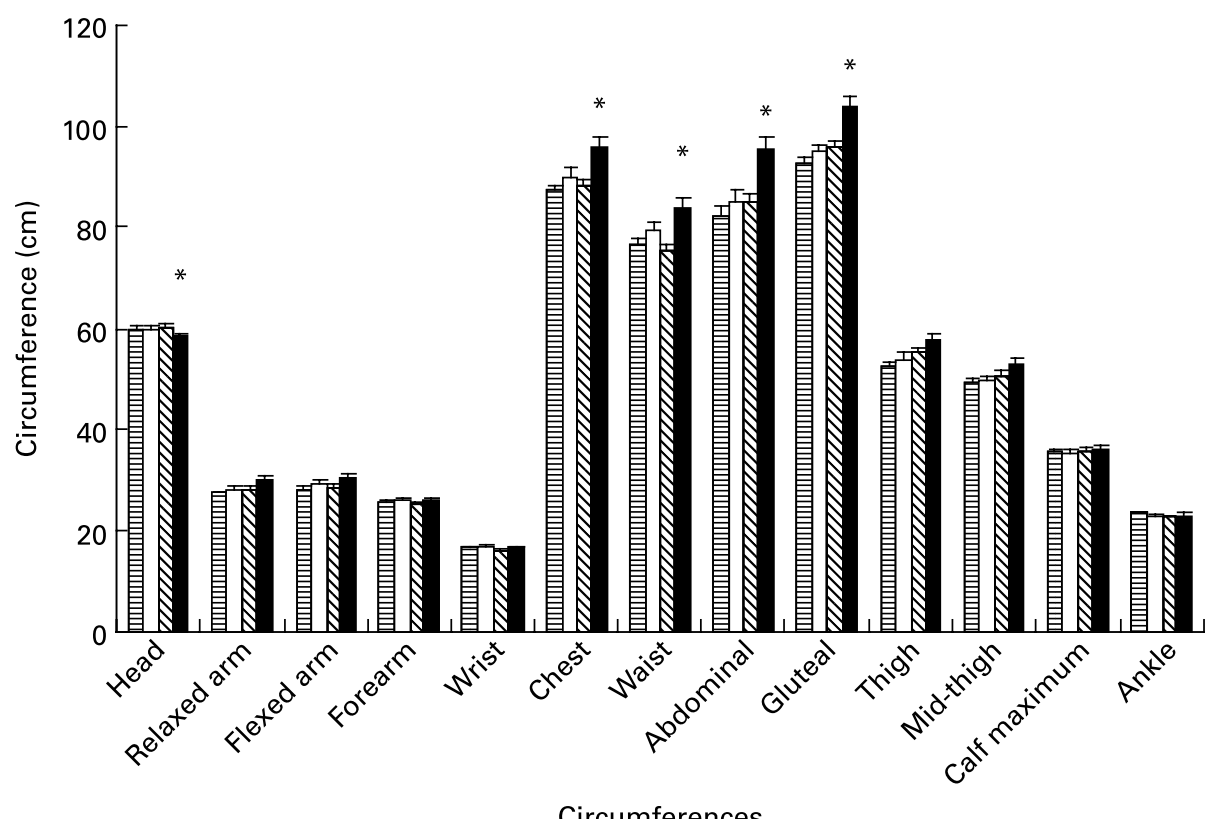

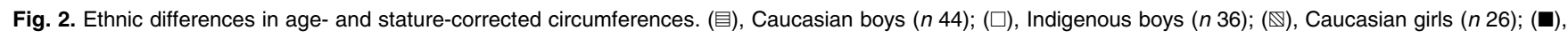
Indigenous girls $(n$ 38). Values are means, with standard errors represented by vertical bars. * Mean value was significantly different from that of the Caucasian girls after controlling for the effects of age and stature $(P<0.05)$.

girls $=0 \cdot 93$ ). After adjustment for age, fat accumulation in the android ROI relative to total fat reached significance in boys (Caucasian boys, 6.2\%; Indigenous boys, 6.8\%; $P<0.05$ ).

The best predictive models ( $>93 \%$ of variation) for total and android fat in boys and girls were obtained from $\Sigma$ SF and age (Table 3). Other models which accounted for more than $70 \%$ of the variation included combinations of age, ethnicity (for girls not boys), abdominal circumference, AHtR, body mass and BMI. The relationship between body composition variables and BMI was not influenced by age and tended to be weaker than $\mathrm{SSF}$, abdominal circumference or AHtR. Despite the lack of ethnic influence in boys in

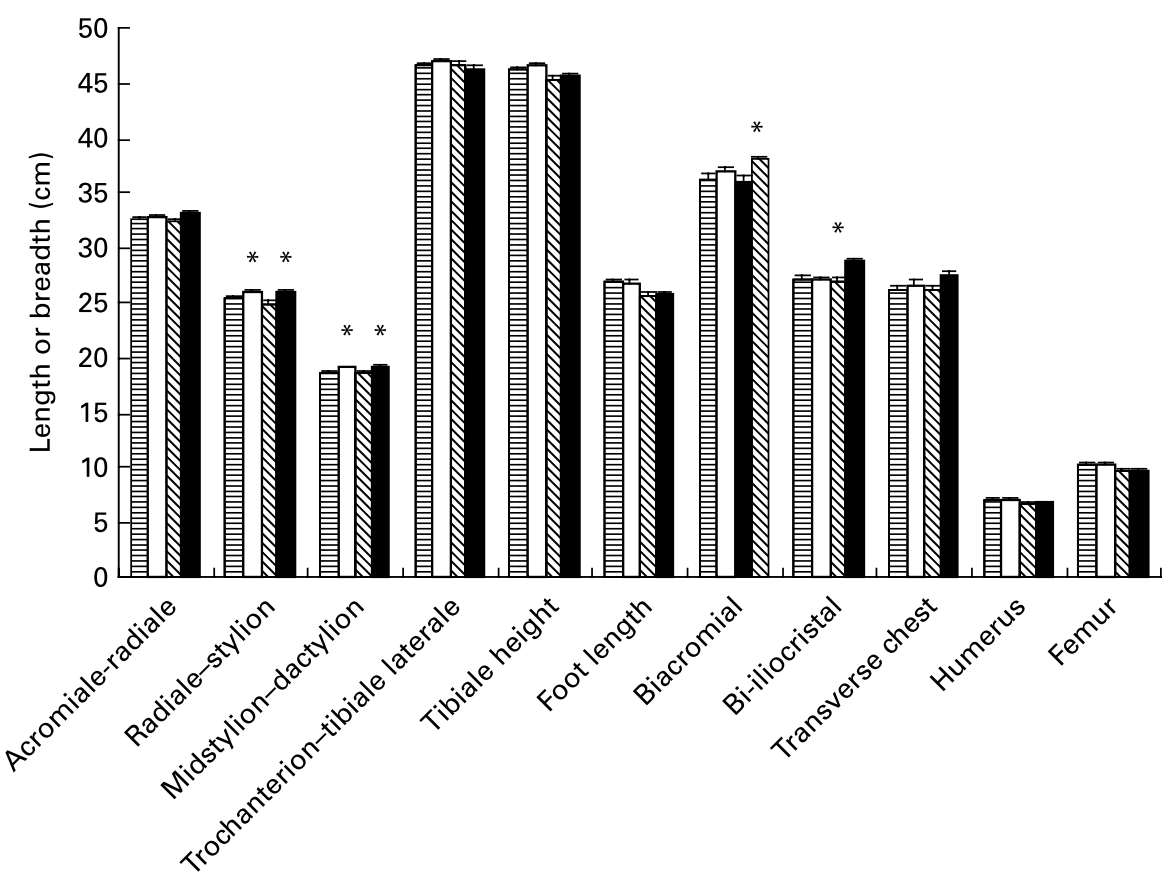

Bone lengths and breadths

Fig. 3. Ethnic differences in age- and stature-corrected lengths and bone breadths. (目), Caucasian boys ( $n$ 44); ( $\square$ ), Indigenous boys ( $n 36)$; ( $\mathbb{8}$ ), Caucasian girls ( $n$ 26); ( $\mathbf{\square})$, Indigenous girls ( $n$ 38). Values are means, with standard errors represented by vertical bars. * Mean value was significantly different from that of the Caucasian group of the same sex after controlling for the effects of age and stature $(P<0.05)$. 
Table 2. Ethnic differences in anthropometric and body composition indices (Mean values with their standard errors)

\begin{tabular}{|c|c|c|c|c|c|c|c|c|}
\hline \multirow{3}{*}{$\begin{array}{l}\text { Sex... } \\
\text { Ethnicity... }\end{array}$} & \multicolumn{4}{|c|}{ Boys } & \multicolumn{4}{|c|}{ Girls } \\
\hline & \multicolumn{2}{|c|}{ Caucasian ( $n$ 44) } & \multicolumn{2}{|c|}{$\begin{array}{l}\text { Indigenous } \\
\quad(n 36)\end{array}$} & \multicolumn{2}{|c|}{ Caucasian $(n 26)$} & \multicolumn{2}{|c|}{$\begin{array}{l}\text { Indigenous } \\
\quad(n 38)\end{array}$} \\
\hline & Mean & SE & Mean & SE & Mean & SE & Mean & $\mathrm{SE}$ \\
\hline Arm lengths relative to stature & $0.45^{\star}$ & 0.002 & 0.46 & 0.002 & $0.45^{\star}$ & 0.004 & 0.46 & 0.002 \\
\hline Leg lengths relative to stature & 0.54 & 0.002 & 0.55 & 0.003 & 0.54 & 0.004 & 0.54 & 0.002 \\
\hline Abdominal:height ratio & 0.48 & 0.01 & 0.50 & 0.015 & $0.50^{*}$ & 0.01 & 0.56 & 0.01 \\
\hline Waist:hip ratio & 0.82 & 0.006 & 0.83 & 0.008 & $0.79^{*}$ & 0.008 & 0.80 & 0.008 \\
\hline Percentage android fat (\%) & $24 \cdot 3$ & $2 \cdot 0$ & $27 \cdot 4$ & $2 \cdot 5$ & 33.7 & $2 \cdot 3$ & $39 \cdot 6$ & $2 \cdot 2$ \\
\hline Percentage gynoid fat (\%) & $31 \cdot 8$ & 1.5 & $32 \cdot 2$ & 1.9 & 39.9 & 0.3 & $42 \cdot 7$ & 1.3 \\
\hline Android fat relative to total fat (\%) & $6 \cdot 2^{*}$ & 0.2 & $6 \cdot 8$ & 0.2 & $6 \cdot 8$ & 0.3 & 7.5 & 0.2 \\
\hline Trunk:total fat mass ratio & $0.39^{*}$ & 0.009 & 0.43 & 0.01 & $0.43^{*}$ & 0.01 & 0.48 & 0.008 \\
\hline Legs:total fat mass ratio & $0.47^{\star}$ & 0.009 & 0.43 & 0.008 & 0.43 & 0.01 & 0.40 & 0.008 \\
\hline Limbs:trunk fat mass ratio & $1.49^{\star}$ & 0.06 & $1 \cdot 21$ & 0.05 & $1 \cdot 26^{\star}$ & 0.05 & 1.04 & 0.03 \\
\hline Android:gynoid fat ratio & 0.71 & 0.03 & 0.79 & 0.006 & 0.81 & 0.007 & 0.89 & 0.03 \\
\hline
\end{tabular}

* Mean value was significantly different from that of the Indigenous group of the same sex after controlling for the effect of age $(P<0.05)$.

relationships involving total and android fat, relationships between abdominal circumference and android fat tissue were consistent regardless of ethnicity in Indigenous girls who tended to have a smaller amount of total fat tissue mass at a given abdominal circumference (Fig. 4). Results also indicated that Indigenous girls were likely to have a smaller total or android fat tissue at a given AHtR calculated from the abdominal circumference.

\section{Discussion}

To the best of our knowledge, this is the first study to undertake a comprehensive anthropometric and body composition assessment on Caucasian and Indigenous children and adolescents living in an urban Australian setting. The study confirmed a striking sex difference in body composition and anthropometric indices between ethnic groups.

After adjustment for age, we found that Indigenous and Caucasian children were similar in stature and body mass. However, these findings were inconsistent with previous studies that reported significantly smaller body mass and stature in Aboriginal children ${ }^{(10,18)}$ which may in part be attributed to a difference in geographical location of respective study cohorts. Previous studies used Aboriginal children living in rural areas where growth retardation is common ${ }^{(19,20)}$ due to both poor maternal nutrition ${ }^{(21)}$ and food availability $^{(22)}$.

Table 3. Prediction of total and android fat using selected anthropometric indices $† \S$

(Adjusted correlation coefficients and standard errors of the estimate)

\begin{tabular}{|c|c|c|c|c|c|}
\hline Sex & Dependent variable & Anthropometric index & Regression equations & $R_{\mathrm{ad}}^{2}$ & SEE \\
\hline \multirow{10}{*}{ Boys } & Ln total fat $(\mathrm{g})$ & $\Sigma S F$ & $3.025+1.194 \times \operatorname{Ln}(\Sigma S F)+0.058 \times$ age & 0.943 & 0.161 \\
\hline & & $A C$ & $-7.510+4.068 \times \operatorname{Ln}(A C)-0.072 \times$ age & 0.901 & 0.213 \\
\hline & & $\mathrm{AHtR}$ & $11.111+4.101 \times \operatorname{Ln}(\mathrm{AHtR})+0.085 \times$ age & 0.831 & 0.278 \\
\hline & & BMI & $0.194+2.996 \times \operatorname{Ln}(\mathrm{BMI})$ & 0.819 & 0.288 \\
\hline & & BM & $9.152+0.045 \times \mathrm{BM}-0.181 \times$ age & 0.707 & 0.367 \\
\hline & Ln android fat $(\mathrm{g})$ & $\Sigma$ TrunkSF & $6.153+1.232 \times \operatorname{Ln}\left(\sum\right.$ TrunkSF $)$ & 0.947 & 0.197 \\
\hline & & $A C$ & $-14.540+5.103 \times \operatorname{Ln}(A C)-0.089 \times$ age & 0.899 & 0.270 \\
\hline & & $\mathrm{AHtR}$ & $8.795+5.101 \times \operatorname{Ln}(\mathrm{AHtR})+0.108 \times$ age & 0.814 & 0.367 \\
\hline & & BMI & $-4.750+3.725 \times \operatorname{Ln}(\mathrm{BMI})$ & 0.802 & 0.379 \\
\hline & & BM & $6.364+0.056 \times \mathrm{BM}-0.226 \times$ age & 0.706 & 0.462 \\
\hline \multirow[t]{10}{*}{ Girls } & Ln total fat $(\mathrm{g})$ & $\Sigma S F$ & $3.050+1.137 \times \operatorname{Ln}(\Sigma S F)+0.079 \times$ age & 0.951 & 0.133 \\
\hline & & $A C$ & $-5.115+3.366 \times \operatorname{Ln}(A C)-0.131 \times$ ethnicity & 0.951 & 0.132 \\
\hline & & $\mathrm{AHtR}$ & $10.928+3.592 \times \operatorname{Ln}(\mathrm{AHtR})+0.091 \times$ age $-0.196 \times$ ethnicity & 0.905 & 0.185 \\
\hline & & BM & $8.256+0.040 \times \mathrm{BM}-0.061 \times$ age & 0.878 & 0.210 \\
\hline & & BMI & $1.924+2.510 \times \operatorname{Ln}(\mathrm{BMI})$ & 0.864 & 0.221 \\
\hline & Ln android fat $(\mathrm{g})$ & ¿TrunkSF & $5.317+1.233 \times \operatorname{Ln}(\Sigma$ TrunkSF $)+0.067 \times$ age & 0.934 & 0.194 \\
\hline & & $A C$ & $-11.341+4.276 \times \operatorname{Ln}(A C)-0.042 \times$ age & 0.922 & 0.211 \\
\hline & & $\mathrm{AHtR}$ & $9.024+4.632 \times \operatorname{Ln}(\mathrm{AHtR})+0.084 \times$ age $-0.196 \times$ ethnicity & 0.884 & 0.258 \\
\hline & & BMI & $-2.452+3.074 \times \operatorname{Ln}(\mathrm{BMI})$ & 0.813 & 0.327 \\
\hline & & BM & $5.515+0.05 \times \mathrm{BM}-0.098 \times$ age & 0.811 & 0.329 \\
\hline
\end{tabular}

$\Sigma S F$, sum of eight skinfolds; AC, abdominal circumference; AHtR, abdominal:height ratio; BM, body mass; $\Sigma$ TrunkSF, sum of trunk skinfolds.

† One Caucasian boy declined to have his iliac crest skinfold thickness measured; therefore forty-three Caucasian boys were available for $\Sigma$ SF and $\Sigma$ TrunkSF.

$\ddagger$ Ethnicity: 1 = Indigenous; $0=$ Caucasian.

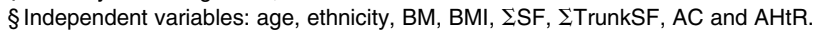



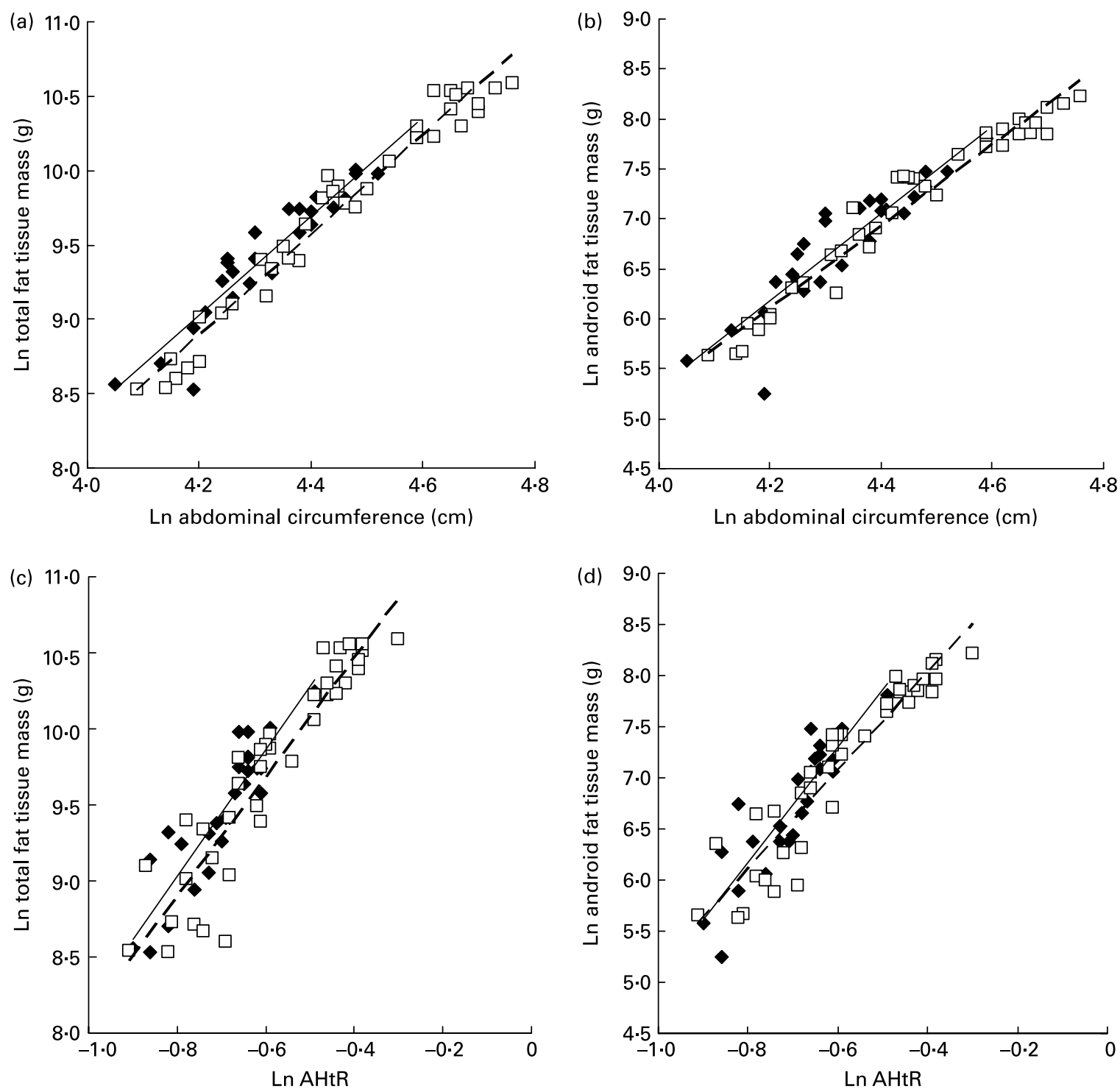

Fig. 4. Scatter plots of abdominal circumference and abdominal:height ratio (AHtR) using total fat and android fat tissues in Caucasian ( $n$ 26; $\bullet$ ) and Indigenous $(n$ 38; $\square$ ) girls. (a) Relationship between abdominal circumference and total fat tissue. (b) Relationship between abdominal circumference and android fat tissue. (c) Relationship between AHtR and total fat tissue. (d) Relationship between AHtR and android fat tissue. While no ethnic difference in the relationship between abdominal circumference and android fat tissue was observed, Indigenous girls showed a smaller amount of total body fat at given abdominal circumference $(P<0.05)$. Similarly, Indigenous girls showed a smaller amounts of both total and android fat tissues at the given AHtR compared with Caucasian girls $(P<0.05)$.

According to Barker's 'fetal origin theory', children who are born undernourished have a greater risk of developing obesity and related health problems ${ }^{(23)}$, considered one of the causes of poor health status in the Indigenous population. In the present study, a greater proportion of Indigenous children were overweight or obese, consistent with previous findings that children living in urban areas tend to be larger and have higher BMI than those living in rural areas ${ }^{(24)}$. There is also a higher prevalence of obesity among Indigenous adults of high socio-economic status ${ }^{(25)}$ due to the nutrition transition experienced by the Indigenous population in urban areas.

The present study also confirmed that ethnic differences in anthropometry are more significant in girls than boys, with Indigenous girls having greater relative trunk circumferences and indices including AHtR and waist:hip ratio. The mean value for AHtR suggests that Indigenous girls have an abdominal circumference $10 \mathrm{~cm}$ greater than Caucasian girls for a given stature, indicative of a larger proportion of abdominal fat. Tendency for a greater subcutaneous fat deposition (as measured as skinfold thickness) among Indigenous children is also consistent with the higher deposition of abdominal fat subcutaneously than Caucasian children. Previous studies have reported that Caucasians and Asians are predisposed to greater visceral fat deposition than Africans ${ }^{(26-29)}$, with the present results indicative of similarity in the pattern of abdominal fat distribution in Indigenous and African populations. A significant ethnic difference in fat accumulation in the android ROI was only found in boys, which may be due to the small number of Caucasian girls and also the possibility 
that Indigenous girls had greater fat deposition in both the abdomen and chest.

The study also revealed ethnic differences in fat distribution between the trunk and limbs, with Caucasian children showing a lower proportion of fat in the trunk despite no ethnic differences in total tissue mass and body fat percentage. Caucasian children also showed a greater fat deposition in their limbs relative to trunk, although Indigenous children have longer arms and also comparable total tissue mass. Results also suggest that Indigenous children are likely to have a physique with leaner limbs and greater fat accumulation in the trunk than Caucasians at a given total tissue mass, consistent with results in previous studies ${ }^{(30,31)}$. As effect size was calculated for ethnic differences in arm length and fat distribution ratio between the limbs and the trunk, results may suggest biologically significant physical differences.

In the present study, relationships between total and android fat tissue and commonly used anthropometric indices were also examined. Results indicate that $\Sigma$ SF and abdominal circumference are useful measures of total or regional fat accumulation in both sexes. These indices also showed an influence of age, indicative that maturation significantly influences the increased fat deposition in the study population. Caucasian and Indigenous girls had a comparable amount of android fat tissue at a given abdominal circumference; however, Indigenous girls were likely to have significantly less android fat when AHtR was calculated from measured abdominal circumference. It has been suggested that AHtR or waist:height ratio may be a useful screening index for abdominal obesity across age, sex and ethnicity ${ }^{(32-34)}$; however, the ethnic difference in the present study (despite no difference in body size) suggests caution in the use of this index in Indigenous children. Further research on ethnic differences in AHtR and abdominal fat deposition/distribution pattern, along with associations with metabolic health risks is warranted. Apart from abdominal circumference and AHtR in girls, there were no ethnic differences in relationships between common anthropometric indices, including BMI, and body composition variables in the present study. Despite ethnic differences in body fat distribution pattern it is possible to use the same cut-off points for anthropometric indices to determine metabolic health risks in both Caucasian and Indigenous children. These findings differ from an earlier study of adults ${ }^{(9)}$ and another in which Caucasian, Maori and Pacific Islander children living in New Zealand were compared ${ }^{(12)}$.

The classification method used to identify ethnic background may also be an important factor to consider. In the present study, identification of both parents or guardians and community recognition were used to categorise the background of participants. The urban-dwelling Indigenous population is a diverse mix of different ethnic backgrounds, including Aboriginals, Torres Strait Islanders, Caucasians, Asians and South Pacific Islanders. As a result, a major limitation of the present study, and possibly one of the reasons for minimal ethnic differences in the majority of anthropometric indices and body composition variables, may be the 'similarities' between groups. It is also important to stress that only a small proportion of the Indigenous population has maintained their traditional lifestyle. As the definition of 'Aboriginal' used was consistent with that used by Australian law, we can be confident that the present results are reflective of differences in the physical characteristics between Caucasian and Indigenous children. In addition, the study provides confirmation of the applicability of the same anthropometric cut-off points for the metabolic screening of Indigenous children living in an urban setting.

Finally, this is the first study to provide comprehensive anthropometric and body composition information of Indigenous compared with Caucasian children living in urban Australia. The results confirmed the comparability of physical characteristics in boys and the presence of some distinct differences between girls of different ethnic backgrounds, including the proportion of overweight and obese. Results also indicated possible ethnic differences in fat distribution patterns including visceral-subcutaneous and trunk-extremities. However, relationships between anthropometric indices and selected body composition variables showed no ethnic influence in boys and minimal impact in girls. The findings, despite the relatively modest sample size, tentatively confirm the appropriateness of similar screening tools being used to prevent childhood obesity and children at risk of future metabolic complications. Due to the small sample size of the study as well as lack of information about socio-economic status and pubertal stages of the children, it is strongly recommended that future research should be conducted on a larger cohort with inclusion of both social and biological information.

\section{Acknowledgements}

The authors would like to acknowledge the Aboriginal and Islander Independent Community School (Murri School), particularly Mr Victor Hart, the Manager of Queensland University of Technology's Oodgeroo Unit as well as the Deputy President of the Aboriginal and Islander Independent School (Murri School), for their invaluable support in relation to engagement with the Murri School.

The study was supported by an ATN Centre for Metabolic Fitness grant.

All co-authors contributed to the preparation of the manuscript. M. K. contributed to the project design, data collection, data analysis and preparation of the manuscript. N. M. B, N. A. $K$. and S. P. contributed to the preparation of the manuscript and A. P. H. contributed as a supervisor and to the preparation of the manuscript.

There were no conflicts of interest in the present study to declare.

\section{References}

1. Trewin D (2006) National Aboriginal and Torres Strait Islander Health Survey 2004-05. Canberra: Australian Bureau of Statistics.

2. Craig ME, Femia G, Broyda V, et al. (2007) Type 2 diabetes in Indigenous and non-Indigenous children and adolescents in New South Wales. Med J Aust 186, 497-499.

3. McDermott RA, McCulloch BG, Campbell SK, et al. (2007) Diabetes in the Torres Strait Islands of Australia: better clinical systems but significant increase in weight and other risk conditions among adults, 1999-2005. Med J Aust 186, 505-508.

4. Thorburn AW (2005) Prevalence of obesity in Australia. Obes Rev 6, 187-189. 
5. Wang Z \& Hoy WE (2004) Waist circumference, body mass index, hip circumference and waist-to-hip ratio as predictors of cardiovascular disease in Aboriginal people. Eur J Clin Nutr 58, 888-893.

6. Jones CO \& White NG (1994) Adiposity in aboriginal people from Arnhem Land Australia: variation in degree and distribution associated with age, sex and lifestyle. Ann Hum Biol 21, 207-227.

7. Deurenberg P, Yap M \& van Staveren WA (1998) Body mass index and percent body fat: a meta analysis among different ethnic groups. Int J Obes 22, 1164-1171.

8. Kagawa M, Kerr D, Uchida H, et al. (2006) Differences in the relationship between BMI and percentage body fat between Japanese and Australian-Caucasian young men. Br J Nutr 95, $1002-1007$.

9. Piers LS, Rowley KG, Soares MJ, et al. (2003) Relation of adiposity and body fat distribution to body mass index in Australians of Aboriginal and European ancestry. Eur J Clin Nutr 57, 956-963.

10. Hitchcock NE, Gracey M, Maller RA, et al. (1987) Physical size of 1887 Aboriginal schoolchildren in the Kimberley region. Med J Aust 146, 415-419.

11. Deurenberg P, Deurenberg-Yap M, Foo LF, et al. (2003) Differences in body composition between Singapore Chinese, Beijing Chinese and Dutch children. Eur J Clin Nutr 57, 405-409.

12. Rush EC, Puniani K, Valencia ME, et al. (2003) Estimation of body fatness from body mass index and bioelectrical impedance: comparison of New Zealand European, Maori and Pacific Island children. Eur J Clin Nutr 57, 1394-1401.

13. National Health and Medical Research Council (1999) National Statement on Ethical Conduct in Research Involving Humans. Canberra: NHMRC

14. International Society for the Advancement of Kinanthropometry (2001) International Standards for Anthropometric Assessment. Canberra: ISAK.

15. Gore C, Norton K \& Olds T (1996) Accreditation in anthropometry: an Australian model. In Anthropometrica, pp. 395-411 $[\mathrm{K}$ Norton and $\mathrm{T}$ Olds, editors]. Sydney: University of New South Wales Press.

16. Carter JEL \& Heath BH (1990) Somatotyping - Development and Application. Cambridge: Cambridge University Press.

17. Cole TJ, Bellizzi MC, Flegal KM, et al. (2000) Establishing a standard definition for child overweight and obesity worldwide: international survey. BMJ 320, 1240-1245.

18. Goran MI, Allison DB \& Poehlman ET (1995) Issues relating to normalization of body fat content in men and women. Int $J$ Obes 19, 638-643.

19. Ruben AR \& Walker AC (1995) Malnutrition among rural aboriginal children in the Top End of the Northern Territory. Med J Aust 162, 400-403.

20. Rousham EK \& Gracey M (1997) Persistent growth faltering among aboriginal infants and young children in north-west Australia: a retrospective study from 1969 to 1993. Acta Paediatr 86, 46-50.
21. Sayers S \& Powers J (1997) Risk factors for aboriginal low birthweight, intrauterine growth retardation and preterm birth in the Darwin Health Region. Aust N Z J Public Health 21, 524-530.

22. Lee AJ, Darcy AM, Leonard D, et al. (2002) Food availability, cost disparity and improvement in relation to accessibility and remoteness in Queensland. Aust $N Z J$ Public Health 26, 266-272.

23. Barker DJ \& Clark PM (1997) Fetal undernutrition and disease in later life. Rev Reprod 2, 105-112.

24. Reyes ME, Tan SK \& Malina RM (2003) Urban-rural contrasts in the growth status of school children in Oaxaca. Mexico. Ann Hum Biol 30, 693-713.

25. Lourenço AE, Santos RV, Orellana JD, et al. (2008) Nutrition transition in Amazonia: obesity and socioeconomic change in the Suruí Indians from Brazil. Am J Hum Biol 20, 564-571.

26. Deurenberg P, Bhaskaran K \& Lian PL (2003) Singaporean Chinese adolescents have more subcutaneous adipose tissue than Dutch Caucasians of the same age and body mass index. Asia Pacific J Clin Nutr 12, 261-265.

27. Lovejoy JC, de la Bretonne JA, Klemperer M, et al. (1996) Abdominal fat distribution and metabolic risk factors: effects of race. Metabolism 45, 1119-1124.

28. Tanaka S, Horimai C \& Katsukawa F (2003) Ethnic differences in abdominal visceral fat accumulation between Japanese, African-Americans, and Caucasians: a meta-analysis. Acta Diabetol 40, S302-S304.

29. Kadowaki T, Sekikawa A, Murata K, et al. (2006) Japanese men have larger areas of visceral adipose tissue than Caucasian men in the same levels of waist circumference in a population-based study. Int J Obes 30, 1163-1165.

30. He Q, Horlick M, Thornton J, et al. (2002) Sex and race differences in fat distribution among Asian, African-American, and Caucasian prepubertal children. J Clin Endocrinol Metab 87, 2164-2170.

31. Byrne NM, Weinsier RL, Hunter GR, et al. (2003) Influence of distribution of lean body mass on resting metabolic rate after weight loss and weight regain: comparison of responses in white and black women. Am J Clin Nutr 77, 1368-1373.

32. Ashwell M \& Hsieh SD (2005) Six reasons why the waist-toheight ratio is a rapid and effective global indicator for health risks of obesity and how its use could simplify the international public health message on obesity. Int J Food Sci Nutr 56, 303-307.

33. McCarthy HD \& Ashwell M (2006) A study of central fatness using waist-to-height ratios in UK children and adolescents over two decades supports the simple message - 'keep your waist circumference to less than half your height'. Int J Obes 30, 988-992.

34. Kagawa M, Hills AP \& Binns CW (2007) The usefulness of the waist-to-height ratio to predict trunk fat accumulation in Japanese and Australian Caucasian young males living in Australia. Int J Body Comp Res 5, 57-63. 